\title{
Aspectos da identidade de surdos no âmbito da formação superior ${ }^{1}$
}

\author{
Alline Nunes Andrade* \\ Heloisa Moulin de Alencar**
}

\section{Resumo}

Refletiu-se sobre as identidades de indivíduos surdos em uma perspectiva ética. A pergunta "Quem eu sou?" relaciona-se com reflexóes sobre a vida boa, sendo necessário o processo de tomada de consciência de si e a constituição da função simbólica para definição identitária. A comunicação é aspecto central neste estudo considerando-se que a maioria dos surdos sofre o atraso na aquisição da língua e a exclusão nos processos educacionais. Participaram 16 pessoas surdas que se matricularam em instituiçóes de educação superior. Aplicou-se o método clínico piagetiano, por meio de entrevistas individuais semiestruturadas em língua de sinais, com enfoque nos relatos sobre a aquisição da língua de sinais e a presença de pessoas surdas na família ou em seus relacionamentos afetivos. Os principais dados indicam que sete participantes adquiriram a língua de sinais entre os 19 e 21 anos de idade. A principal categoria de identidade surda foi a de transição. Os auxiliares na aquisição da língua foram principalmente os 'amigos surdos' e as 'pessoas da comunidade surda'. A partir da constituição das identidades surdas, foi possível constatar que a experiência subjetiva de expansão de si foi propiciada no contato com a comunidade surda e sua língua de sinais. Propostas de estudos sobre a constituição da identidade surda em relação com suas projeções de si no futuro podem ser realizadas, contribuindo com a ampliação do estudo sobre a perspectiva ética. No âmbito educacional, recomenda-se que as escolas bilíngues sejam espaço privilegiado de interações linguísticas e desenvolvimento do potencial comunicativo de crianças surdas.

Palavras-chave: Identidade surda; Perspectiva ética; Aquisição de língua de sinais.

\footnotetext{
* Doutora em Psicologia, Pesquisadora Tecnologista em Avaliaçôes e Informaçốs Educacionais do Institucional Nacional de Estudos e Pesquisas Educacionais Anísio Teixeira - INEP, Brasília, Distrito Federal, Brasil

** Doutora em Psicologia, Professora do Departamento de Psicologia Social e do Desenvolvimento (DPSD) e do Programa de Pós-Graduação em Psicologia (PPGP) da Universidade Federal do Espírito Santo - UFES, Vitória, Espírito Santo, Brasil.
} 


\section{Aspects of deaf identity in the context of higher education}

\section{Abstract}

It was reflected on the identities of deaf individuals in an ethical perspective. The question "Who am I?" is related to reflections on the good life, being necessary to the process of awareness of self and the constitution of the symbolic function to define a personal identity. The communication is central to this study, considering that most deaf suffer delays in language acquisition and exclusion in educational processes. Participated 16 deaf people who had enrolled in higher education institutions. It used the Piaget's clinical method through individual semistructured interviews in sign language, focused on the reports on the acquisition of sign language and the presence of deaf people in the family or in their romantic relationships. The main data indicate that seven participants acquired sign language between 19 and 21 years old. The main category of deaf identity was the transition's identity. The auxiliary people in language acquisition were mainly 'deaf friends' and 'people of the deaf community'. From the establishment of deaf identities, it was found that the subjective experience of expansion itself was caused in contact with the deaf community and sign language. Proposals for studies on the establishment of deaf identity in relation to their projections of themselves in the future can be made, contributing to the expansion of the study of the ethical perspective. In education, it is emphasized that the bilingual schools are privileged space of language interactions and development of communicative potential of deaf children.

Keywords: Deaf identity; Ethical perspective; Acquisition of sign language.

\section{Introdução}

Este estudo reflete sobre as identidades de pessoas surdas que haviam se matriculado em instituições de educação superior, com enfoque no processo de aquisição de Língua de Sinais Brasileira (Libras) e na existência de pessoas surdas na família ou em seus relacionamentos afetivos. Tal reflexáo articula-se com o campo da Psicologia da Moralidade, quanto às representaçôes positivas de si e à vivência do sentimento de expansão de si (LA TAILLE, 2006; RICOEUR, 2004/2006).

De acordo com La Taille (2006), no plano ético, a experiência subjetiva de alguma forma de bem-estar, a avaliação de que essa experiência segue o fluxo temporal da vida, a existência de sentido para a vida e a possibilidade de realização da expansão de si próprio são elementos invariáveis.

Ricoeur (2004/2006) afirma que um sujeito da ação só poderá qualificar a sua vida sob a perspectiva ética se essa vida puder ser relatada, pois a pessoa passa a ter conhecimento da extensão de sua vida, reconhecendo que é portadora de outras capacidades. Narrar-se depende da constituição da função simbólica, condição necessária para que a capacidade de representação se instaure. 
A linguagem é uma das modalidades de representação do pensamento que possibilita ao indivíduo evocar objetos para os quais tenham se dirigido suas condutas, reconstituir o passado e antecipar as açôes futuras (PIAGET, 1964/1991). Ela favorece o acesso ao pensamento formal, mas também a imersão e os intercâmbios com os outros indivíduos possibilitarão ao pensamento infantil a interiorização das açóes, suporte em linguagem interior e em um sistema de signos.

A constituição da função simbólica é condição para o processo de tomada de consciência implicando na questão da identidade pessoal. Quando o sujeito constrói a própria identidade, "não é apenas a sua existência biológica que ele concebe, mas também, e sobretudo, sua existência como ser social, sua inserçấo no seio de um grupo, suas relaçôes com outrem, etc." (LA TAILLE, 2006, p. 45). A identidade pessoal se constrói mediante contínuas tomadas de consciência das próprias açóes sobre o mundo e conquistará, quando "o mundo dos possíveis [for] concebido de forma operatória” (p. 46), a capacidade de reflexão das referidas tomadas de consciência.

Nesse sentido, é relevante refletir sobre a condição de pessoas que, biologicamente impedidas de adquirirem os signos linguísticos via modalidade auditiva, podem vivenciar o processo de aquisição tardia de uma língua, o que não costuma ocorrer com as pessoas cujo acesso a uma língua natural é estimulado precocemente.

Sixel (2005) observou contextos de interação linguística em língua de sinais em uma escola especializada para surdos. Os participantes eram crianças e adolescentes surdos que tinham entre 9 e 15 anos de idade com média no tempo de uso da língua de sinais de 4,4 anos no momento da realizaçáo da pesquisa. Constatou-se que "o contato sistemático com uma língua estruturada mostrou-se capaz de minimizar os efeitos da exposição tardia aos jogos de linguagem que os seres humanos travam em suas interaçôes desde os primeiros dias de vida" (SIXEL, 2005, p. 129)

Para Skliar, Massone e Veinberg (1995), é possível caracterizar a surdez a partir de um modelo clínico da surdez ou ir além de uma explicação etiológica, considerando o sujeito surdo como parte de uma comunidade para a qual a língua de sinais exerce um papel fundamental. Neste modelo destaca-se uma perspectiva socioantropológica da surdez. O enfoque clínico da surdez impóe "uma visão estritamente ligada à patologia, ao déficit biológico e deriva inevitavelmente em estratégias e em recursos de natureza reparadora e corretiva ${ }^{2 "}$ (SKLIAR, MASSONE, VEINBERG, 1995, p. 2). Pelo fato de não ouvir e, consequentemente, não falar, o sujeito surdo é rotulado a partir da falta, restando um tratamento e uma proposta educacional de reabilitação.

Dalcin $(2005$, p. 2) interroga em que medida "os filhos surdos de pais ouvintes incorporam a cultura de sua família e sentem-se membros da mesma” (p. 2), considerando que esses surdos se definem como estrangeiros no próprio meio familiar. Com auxílio de uma intérprete de Libras, a autora entrevistou surdos adultos, filhos de pais ouvintes, que adquiriram a língua de sinais a partir da adolescência e faziam parte da comunidade surda. Em relação ao período anterior à aquisição de Libras, os relatos dos participantes ilustram "a precariedade simbólica a que estavam submetidos" (DALCIN, 2005, p. 103). Esses sujeitos "ficavam como que num estado de 'limbo', 
pois lhes faltavam as ferramentas para poder construir os conceitos, manipulá-los, fazer cadeia associativa" (DALCIN, 2005, p. 104).

Conforme Nader (2011, p. 97-98), embora não existam estudos sobre a relação entre a aquisição tardia de língua de sinais e uso de gestos caseiros, "é de esperar que as relaçóes entre os sistemas simbólicos - gestual e linguístico -, as possibilidades interativas e a posição do surdo como sujeito da linguagem, mesmo antes de ter uma língua, tenham influência nos processos de aquisição". Entretanto, a autora ressalta que a ausência da língua limita o desenvolvimento da comunicação e da cogniçáo, impedindo a estruturação de funçóes complexas do pensamento. Ao lembrar-se do seu processo de aquisiçáo tardia de língua de sinais, Laborit (1994/2000) revela que, aos poucos, foi possível a ela constatar que atos e palavras determinadas correspondiam, assim como havia correlação entre atos e as pessoas que os produziam: "de súbito o mundo pertencia-me e eu fazia parte dele. [...] Nascera e crescera de uma só vez. Tinha tanta fome e sede de aprender, de conhecer, de compreender o mundo que desde entâo nunca mais parei” (p. 4).

O contato entre surdos ainda não sinalizadores e as geraçôes de surdos usuários de língua de sinais tem sido relatado por autores surdos (LABORIT, 1994/2000; W. de O. MIRANDA, 2007; PERLIN, 1998, 2003; STROBEL, 2009) como um espaço que possibilita vivenciar a descoberta de uma língua e experimentar conforto linguístico.

Antes do reconhecimento legal de Libras, alguns surdos atuavam informalmente como auxiliares em escolas de surdos e transmitiam clandestinamente a língua de sinais, quando prevalecia uma educaçáo oralista. Assim, são comuns os relatos de sujeitos surdos sobre terem sido punidos por usarem a língua de sinais em espaços escolares (ANDRADE, 2006; ANDRADE \& ALENCAR, 2008, 2010, 2012; COSTA, 2007, 2012).

Para Perlin $(1998,2003)$, a subjetividade surda completa-se no contato com o outro surdo. A linguagem utilizada nesse encontro propicia o desenvolvimento da identidade surda, que pode ser constituída como potência, em vez de deficiência. Assim, "ser surdo é uma identidade que se aprende em grupo e só pode ser aprendida no grupo dos surdos" (p. 34). Marcar a diferença surda significa reconhecer a completude do sujeito surdo; por outro lado, assumir a surdez enquanto deficiência implica conceber a possibilidade de corrigi-la, algo que "mantém o surdo pelo meio. É como se dissesse: você é um, mas tem de ser dois ao mesmo tempo" (PERLIN, 1998, p. 63).

Perlin (1998) ressalta que não existe um modelo padrão de identidade, posto serem os surdos diferentes entre si. Para caracterizar essa diversidade, a autora elaborou as categorias 'identidades surdas', 'identidades surdas híbridas', 'identidades de transiçâo', 'identidade surda incompleta' e 'identidades flutuantes'. As 'identidades surdas' designam aqueles sujeitos para quem a comunicação visual é natural. Quando criança, a pessoa surda constitui sua linguagem por meio dos sinais, ampliando seu desenvolvimento à medida que amplia seu vocabulário; quando adulto, o surdo se sobressai militando em prol do acesso por meio da visualidade. Para quem possui a 
identidade surda, essa é uma realidade tranquila, comumente vivenciada por pessoas surdas cujos pais possuem a mesma condição.

Àqueles que nasceram ouvintes e tornaram-se surdos, Perlin (1998) atribui as 'identidades híbridas'. Como esses surdos conhecem a estrutura da língua oral, os conteúdos comunicados são primeiramente codificados em português e, posteriormente, traduzidos para a língua de sinais. Porém, o surdo híbrido, que depende dos sinais e pensa em português, "sente que perdeu aquela parte de todos os ouvintes e você tem pelo meio a parte surda. Você não é um, você é duas metades” (p. 41).

As 'identidades de transição' dizem respeito aos surdos que vivenciaram um longo período sujeitos à representação ouvinte de surdez e, ao encontrar o outro surdo, suas identidades passam por nova significação. Isso ocorre com a maioria dos surdos, uma vez que esses são filhos de pais ouvintes, e suas identidades são de transição, pois ainda ficam resquícios das antigas representaçôes. Perlin (1998) também considera a existência dos surdos que negam sua identidade surda, e tentam reproduzir uma identidade ouvinte; trata-se de pessoas com 'identidade surda incompleta'. Porém, como essas pessoas repelem os outros surdos, mas buscam os ouvintes mesmo sendo rejeitadas por eles devido à inadequação da fala, os surdos com identidade incompleta oscilam entre a rejeição ao povo surdo e a busca pelos ouvintes, sem ter onde se fixar.

Por fim, as 'identidades flutuantes' constituem-se de fragmentos da comunidade surda e do meio ouvinte mutuamente e caracterizam os surdos que "não conseguiram estar a serviço da comunidade ouvinte por falta de comunicação e nem a serviço da comunidade surda por falta da língua de sinais" (p. 46). Apresentam esse tipo de identidade os surdos que, embora conscientes da sua surdez, desejam ser ouvintizados devido às imposiçôes sociais ou aqueles que conformam-se à situação de terem seus comportamentos e aprendizados ditados pelos ouvintes.

Em estudo posterior, Perlin (2003) considera que a individuação do surdo volta-se para o significado de sua diferença e refere-se aos indivíduos com identidade surda como sendo os atores de uma mudança social em prol do povo surdo, em detrimento daqueles sujeitos que narram-se sob a perspectiva da reabilitação. Para Lane (2005), essas pessoas têm um forte sentimento de identificação, pois no mundo surdo é possível vivenciar uma comunicação direta e fácil, bem como desenvolver uma representação positiva de si.

Outros valores considerados por Lane (2005) como fundamentais ao mundo surdo são o fortalecimento do grupo a partir do reconhecimento das contribuiçôes de cada um de seus membros, as decisóes tomadas de forma consensual, a comunidade surda como elemento para a definição de si mesmo, a evidência de um sujeito surdo ao tornar-se membro desse grupo específico, contribuindo com o enriquecimento da língua de sinais e promovendo a divulgação dessas informaçôes às demais pessoas na sociedade.

O histórico de luta e resistência dos surdos, cujo encontro surdo-surdo repercute a produção de um saber linguístico específico, resulta um novo sistema de pensamento relativo à comunidade surda. Costa (2012, p. 97) ressalta que 
"o saber da Libras", como um saber especializado, vai tomando espaço de forma institucionalizada, abrindo caminhos e possibilidades outras de existir a educação bilíngue para os surdos em nossa atualidade, substituindo o especialista em surdez na perspectiva clínica.

Lana, Castro e Marques (2016), todavia, observam que existe um desconhecimento por docentes atuantes na educação superior sobre esses saberes especializados da comunidade surda. Além disso, conforme relato de uma professora surda entrevistada pelas autoras, as próprias instituiçôes de educação superior denotam ignorar as legislaçôes específicas, com destaque para a falta de isonomia nos processos seletivos.

As informações sobre o jeito surdo de ser têm sido apresentadas por meio de estudos empreendidos na educação por autores surdos (W. de O. MIRANDA, 2007; NEMBRI, 2008; PERLIN, 1998, 2003; STROBEL, 2009) ou por estudiosos ligados à comunidade surda (COSTA, 2007, 2012; LANE, 2005). No âmbito da psicologia, Bisol, Simioni e Sperb (2008) verificaram que não somente as pesquisas em psicologia são escassas, como também as poucas existentes tiveram um número restrito de participantes surdos. As autoras constataram que a falta de domínio da língua de sinais pelos pesquisadores dificulta o acesso bem como o estabelecimento de confiança das pessoas surdas em relação ao pesquisador em Psicologia.

De posse dessas informações, investigamos os juízos de pessoas surdas que haviam efetuado matrícula na educação superior sobre o processo de aquisição de Libras e a existência de pessoas surdas na família e/ou em seus relacionamentos afetivos, com o objetivo de discutir sobre a identidade surda.

\section{Método}

\section{Participantes}

Participaram 16 surdos igualmente divididos quanto ao sexo, com idades entre 21 e 40 anos, que já haviam se matriculado em alguma instituição de educação superior, usuários de Libras e provenientes da região da Grande Vitória (ES) e do interior do estado. Os participantes ficaram surdos antes de adquirirem uma linguagem via oral. Todos os entrevistados consentiram sua participaçáo por meio da compreensão e assinatura do Termo de Consentimento Livre e Esclarecido.

\section{Instrumento e procedimentos}

Investigamos informaçôes de caracterização dos participantes, incluindo questóes concernentes à própria surdez e à aquisição de Libras, além de alguns dados socioculturais, por meio dos seguintes conteúdos: idade que ficou surdo; quando e com quem aprendeu Libras; estado civil; (caso seja solteiro/solteira) se possui relacionamento afetivo com alguém; existência de filhos e de outros casos de surdez na família.

As entrevistas foram individuais e filmadas integralmente, pois a comunicação ocorreu por meio da língua de sinais, sem o auxílio de um intérprete de língua de sinais. A filmadora foi posicionada em um ângulo lateral focalizando a entrevistadora e o participante. Os arquivos de vídeo gerados pelas filmagens estấo guardados em 
nosso arquivo pessoal, cuja utilização se restringe aos objetivos da pesquisa, resguardando a identidade dos participantes, que serâo denominados por nomes fictícios, seguido pela idade em anos.

\section{Resultados e discussão}

Apresentaremos os principais dados analisados neste estudo, ressaltando que, em alguns casos, obtivemos um número de respostas e de justificativas superior ao número de participantes.

Os entrevistados informaram que a surdez ocorreu 'ao nascer' $(\mathrm{n}=12)$, 'até doze meses' ( $\mathrm{n}=2)$ e 'dos 13 aos 18 meses' $(\mathrm{n}=2)$. A idade em que ocorre a surdez tem grande impacto no desenvolvimento da criança, considerando que antes dos três anos a experiência linguística via modalidade oral é "muito frágil e ainda não há uma organização da função neurológica” (MARCHESI, 2004, p. 175) para que a criança mantenha sua linguagem interna. No caso das crianças que nascem surdas, a experiência com o som é praticamente inexistente.

Quanto à idade de aquisição da língua de sinais, uma participante desenvolveu a linguagem aproximadamente aos dois anos de idade (Figura 1). Essa entrevistada é oriunda de uma família constituída por surdos sinalizadores, o que possibilitou o contato desde o seu nascimento com uma linguagem visoespacial.

Figura 1 - Demonstrativo do "atraso" em anos na aquisição da língua de sinais pelos participantes

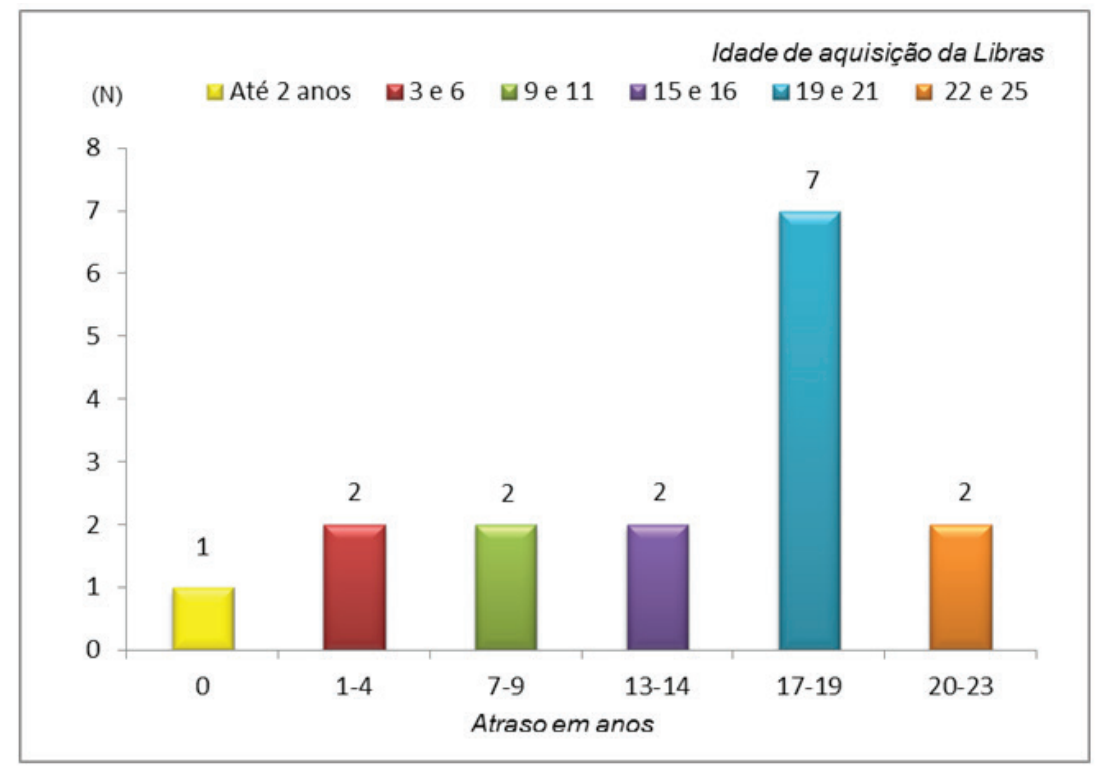


Para sete entrevistados, a aquisição de língua de sinais ocorreu com um atraso de 17 a 19 anos de idade em comparaçáo com a idade prevista para o desenvolvimento usual da linguagem, o que, conforme Piaget (1964/1991), pode ocorrer por volta de um ano e meio a dois anos de idade. Esses dados são semelhantes aos apresentados por Andrade (2006) que, ao entrevistar jovens e adultos surdos, entre 15-25 anos e 35-45 anos de idade, verificou atraso de 7 a 19 anos de idade.

Quanto aos participantes de nosso estudo, comunicar-se por meio de Libras com outras pessoas surdas em igrejas, escolas, associaçóes, entre outros, foi decisivo. Tratam-se de 'amigos surdos' $(\mathrm{n}=10)$, 'pessoas da comunidade surda' $(\mathrm{n}=5)$, 'instrutores em cursos de Libras ( $n=2)$, 'ex-marido surdo' $(n=1)$, 'pais surdos' $(n=1)$ e 'irmá surda' $(\mathrm{n}=1)$.

Esses dados indicam que a comunicação por meio de sinais é compartilhada por poucos familiares dos entrevistados, o que possivelmente se justificaria pelo fato de esses participantes serem, na maioria, filhos de pais ouvintes, com quem prevalecia uma tentativa de comunicaçáo pela via oral. Conforme Laborit (1994/2000), que considera ausência de linguagem o sinônimo de estar condenado a uma vida de solidão, o seu primeiro contato com um surdo adulto e usuário de língua de sinais fez com que ela compreendesse, imediatamente, que "não estava só no mundo" (p. 30). O sentimento de solidáo/isolamento na infância esteve presente nos relatos dos participantes, com exceção de Danielle (21), filha de pais surdos, para quem "tudo tinha um significado", denotando a construçáo de uma identidade surda conforme definido por Perlin (1998). Lana, Castro e Marques (2016) corroboram o referencial do desenvolvimento da língua de sinais e de um sistema de comunicação bilíngue como constitutivo na identidade de uma professora surda, participante de sua pesquisa.

As demais narrativas sobre o processo de aquisição de Libras destacam o papel do outro surdo fora da família, no processo de transição por que passaram os participantes de nossa pesquisa. Esses apresentaram o que Perlin (1998) denominou como sendo identidade de transição, por serem filhos de pais ouvintes e vivenciarem a aquisição da língua de sinais a partir de sua inserção na comunidade surda.

Felipe (24), que aprendeu Libras aos 19 anos, destaca a rapidez como se deu esse processo, caracterizando as pessoas surdas sinalizadoras como acessíveis à comunicação e ao estabelecimento de novas amizades. Em outras palavras, "se eu estiver conversando em Libras com alguém e um surdo nos vir, ele logo vem correndo para se apresentar".

Este participante comentou sobre as inúmeras tentativas de se comunicar oralmente com os ouvintes, após longos anos de terapia oral. A partir do contato com um par surdo Felipe (24) deu-se conta do potencial comunicativo dessa nova modalidade, abandonando, por completo, os exercícios de oralização que eram impostos a ele por seus pais. É possível identificar, nesses relatos, que o contato com os surdos possibilitou-lhes o processo de subjetivação surda que não se restringe ao diagnóstico médico da surdez (Perlin, 2003). 
Para Andressa (28), a sua participação no curso de Letras-Libras possibilitou a ampliação de interaçôes comunicativas, o que não fazia parte da sua realidade, conforme relato a seguir:

Graças a Deus hoje eu estou aprendendo Libras. Antes eu ficava com tudo guardado dentro de mim. A minha vida era junto de ouvintes e só eu surda. Hoje, eu comecei Letras-Libras e eu fiquei fascinada, eu fico babando, eu corro para conversar com as pessoas porque tem comunicação, é gostoso conversar em Libras.

Eduardo (26), que aprendeu Libras aos 19 anos, revela a mágoa que sentiu pela sua mãe ao descobrir que ela omitiu a informação sobre onde as crianças surdas costumavam encontrar-se. De acordo com o participante, ele havia manifestado o desejo de estudar com crianças surdas, pois os colegas ouvintes "desprezavam, brincavam separados". A falta de contato com outros surdos fez com que Eduardo (26) acreditasse que "a maioria de pessoas era ouvinte e só eu era surdo [...].Eu quase acabei com a minha vida, quase morri porque eu não tinha personalidade própria. Minha vida era ruim. Agora, mesmo atrasado, minha vida foi salva”. O autor surdo Nembri (2008) refere-se ao sentimento de solidão na infancia, o qual passou a diminuir quando iniciou contato com os amigos da comunidade surda. $\mathrm{O}$ isolamento na infância também esteve presente no relato de Artur (28), que alegou ter aprendido Libras clandestinamente. Ao referir-se ao momento em que encontrou um surdo que usava língua de sinais pela primeira vez, o participante fez o seguinte relato:

\footnotetext{
Ele me viu e disse: "Você é surdo? Não sabe língua de sinais?". E eu perguntei: "Você é surdo? Língua de sinais, o que é isso?" "Calma! Vem cá, fica quieto, que eu te ensino”. Ele me ensinava rápido e eu aprendia. "Eu tenho medo da professora, não pode língua de sinais, ela vai bater em nossas mãos!" "Fica quieto! Fica junto que eu te ensino". Eu ficava quieto, atento, oralizava e, quando a professora ia embora, eu usava Libras, aprendia, aprendia... Com oito ou nove anos..
}

O relato sobre a aquisição tardia e clandestina de língua de sinais na história de Artur (28) remete-nos a personagens que contribuíram com a ruptura do silêncio imposto aos surdos por meio das práticas oralistas. Os participantes Eduardo (26), Bento (27) e Andressa (28) também informaram que na escola a prática da língua de sinais ocorria escondida dos professores. Costa (2007) reconhece, nesses surdos incentivadores da aquisiçáo da Libras, a característica de terem sido "transgressores" (p. 30) na antiga escola oralista. Ao referir-se a um senhor surdo, responsável pela disseminação da Libras no estado do Espírito Santo, a autora comentou que essa pessoa "ajudava os surdos a manterem em segredo a vida paralela que levavam [e] escondia e criava estratégias de sobrevivência com os surdos na escola de surdos" (p. 84). Em 2012, Costa continuou seu estudo sobre a constituição do professor surdo capixaba, considerando que o saber especializado de Libras vai, aos poucos, assumindo espaço institucional, propiciando outras possibilidades de existir uma educação bilíngue para os surdos, atualmente, "substituindo o especialista em surdez na perspectiva clínica" (p. 97). 
Em suma, as pessoas fundamentais na inserção dos participantes surdos a interações linguísticas foram, na maioria, surdos que faziam parte da comunidade surda, nas escolas orais, de forma clandestina, e nas associaçôes de surdos. Averiguamos, mesmo assim, a existência de pessoas surdas na família, a fim de constatar se a surdez era vivenciada por pessoas próximas dos participantes. Nove deles responderam que tinham os seguintes parentes surdos: 'irmã/irmão' $(\mathrm{n}=7)$, 'tia/tio' $(\mathrm{n}=4)$, 'esposo' $(\mathrm{n}=3)$, 'prima(o) de segundo grau' $(\mathrm{n}=3)$, 'mãe/pai' $(\mathrm{n}=2)$, 'prima(o) de primeiro grau' $(\mathrm{n}=1)$.

Embora o parentesco com maior número seja 'irmã/irmão', apenas um participante referiu-se à irmã surda como apoio no processo de aquisição de Libras, com quem era possível interagir por meio de uma língua de sinais. Uma entrevistada ressaltou que seu irmáo surdo oralizado náo admitia a comunicaçáo por meio de Libras. Assim, a língua de sinais foi encontrada por esses participantes em outro espaço social, marca náo necessariamente compartilhada por todos aqueles que têm o diagnóstico de surdez. Outro participante relembra que, dos cinco filhos surdos na família, ele foi o único a adquirir a língua de sinais.

Existem diferentes identidades surdas (PERLIN, 1998, 2003), que podem caracterizar-se com base no diagnóstico de surdez ou ir além, conforme a perspectiva de surdez como diferença linguística. Diferentemente dos irmãos surdos que não aderiram à língua de sinais, os participantes de nosso estudo parecem assumir para si a identidade surda. Esse processo de construção identitária pode apresentar um caráter dialético, conforme verifica-se no trecho da entrevista com Felipe (24), a seguir: "Dentro da comunidade, eu sou surdo. Fora dela, quando eu vejo o mundo em geral, parece que eu não aceito muito". Para Felipe (24), a representação gráfica de surdez adotada na sociedade, e símbolo da concepção médica de surdez (SKLIAR et al., 1995), não representa o conceito que ele faz de si. O participante identifica a representação de surdez como deficiência por parte da sociedade, o que faz com que esse sujeito retorne à comunidade surda onde ele sente tanto o conforto linguístico pelo uso indiscriminado da língua de sinais quanto o psíquico devido às representaçóes positivas de surdez que são adotadas pela comunidade surda.

Quanto ao estado civil dos entrevistados, nove participantes, dos quais apenas um era do sexo feminino, eram 'solteiros', quatro mulheres eram 'casadas' e três mulheres eram 'divorciadas'. Sobre a condiçấo de surdez do(a) parceiro(a), apenas uma mulher era casada com uma pessoa ouvinte. A maioria ainda não possuía filhos $(\mathrm{n}=11)$, três mulheres eram mães de uma criança ouvinte, uma mulher era mãe de três filhos ouvintes e uma participante estava grávida na ocasião da entrevista. Perguntamos aos solteiros e às mulheres divorciadas se eles namoravam alguém, dos quais seis confirmaram que estavam namorando pessoas surdas.

Sobre o relacionamento afetivo com pessoas surdas, Lane (2005) observa o fato de ser mais comum o casamento entre pessoas surdas. A restrição na comunicação pode ser um dos fatores de influência. Andressa (28), por exemplo, revelou o quanto seu relacionamento conjugal era difícil porque o esposo ouvinte só sinalizava o alfabeto manual, "pouquinho sinal, pouquinho. Então, eu... Como vou falar? Eu fico 
babando com os surdos porque minha cultura de surdos tem língua de sinais. Ele não me entende".

Discutir a identidade surda "não se desvincula da cultura surda, que se relaciona ao processo de recriaçáo de um espaço cultural visual" (LANA, CASTRO, MARQUES, 2016, p. 77), compreensão identificada nas colaborações de diferentes estudiosos da surdez na perspectiva socioantropológica (SKLIAR, MASSONE, VEINBERG, 1997; PERLIN, 1998, 2002; COSTA, 2006, 2012). Sendo o meio educacional central na constituição dessas identidades, lócus de contato entre surdos e de um sistema de comunicação bilíngue, identifica-se uma atuação protagonista assumida pelos surdos no cenário educacional contemporâneo (COSTA, 2012).

\section{Considerações finais}

Os dados apresentados demonstram que não apenas a aquisição de língua de sinais, a qual ocorreu tardiamente para a maioria, mas também o fato de esta ter ocorrido no contato com referenciais surdos mediante inserção na comunidade surda, contribui para a constituição da identidade surda dos participantes.

A principal categoria de identidade surda foi a de transição (PERLIN, 1998), vivenciada pela maioria dos surdos que assumem para si as características da comunidade surda. A língua de sinais possibilitou a esses surdos romper com o silêncio e a solidão que caracterizou sua infância.

A interação desses indivíduos surdos com seus pares parece ter propiciado a vivência de experiências que contribuem para a sensação de viver uma vida boa. A experiência subjetiva da expansão de si próprio, que está atrelada à sensação de bem-estar, à avaliação da própria vida como um continuum e ao reconhecimento do sentido da própria vida, é o elemento que constitui o plano ético (LA TAILLE, 2006). Constatou-se que a aquisiçáo de língua de sinais, embora tardia, e as interaçôes com os seus pares surdos, deram vazáo à expansáo subjetiva dos entrevistados. Ricoeur (2004/2006) compreende que a vida boa é passível de ser assim qualificada por meio da capacidade narrativa do sujeito sobre si. A conquista da linguagem é, portanto, crucial, ao pensarmos a perspectiva ética.

Uma vez que as representaçôes de si podem modificar-se conforme estabelecemos novas relaçóes interindividuais, estudos sobre as escolhas feitas pelo participante no presente, bem como as representaçóes de si no futuro, quando já terão concluído seus estudos de graduaçáo, podem contribuir com a identificação de novos conteúdos de consideração de si e do outro, na tentativa de ampliar o estudo sobre a perspectiva ética em pessoas surdas. Tal proposta pode ainda ser aplicada junto a indivíduos surdos de outras faixas etárias, para uma possível análise comparativa em que se constate a evoluçấo das representaçóes de si com um valor positivo.

Recomenda-se o ingresso de crianças surdas a contextos de interação linguística (SIXEL, 2005), notadamente em escolas bilíngues, de modo a que o processo de desenvolvimento ocorra sem os atrasos provocados pelo acesso tardio à comunicaçáo sistematizada. Sixel (2005) observa que em tais contextos de interaçáo linguística, a 
língua de sinais faz parte de todos os momentos do processo de ensino aprendizagem, assim como ocorre, por exemplo, com uma criança ouvinte na escola comum. A escola é um local privilegiado para promoção de interaçóes linguísticas em língua de sinais, pois é nesse âmbito que os surdos têm demonstrado interesse em atuar como referências identitárias positivas às novas gerações de surdos (COSTA, 2012). Configura-se valor relevante aos surdos que o corpo docente também seja de professores surdos, sem diferenciação negativa pela condição de surdez (LANA, CASTRO, MARQUES, 2016).

\section{Referências}

ANDRADE, A. N. Vozes do silêncio: juízos morais de jovens e adultos surdos sobre situaçôes de humilhação. 228 p. Dissertação (Mestrado em Psicologia). Programa de Pós-Graduação em Psicologia da Universidade Federal do Espírito Santo, Vitória, 2006.

ANDRADE, A. N. \& ALENCAR, H. M. de. Vozes do silêncio: juízos morais de jovens e adultos surdos sobre situaçôes pessoais de humilhação. Boletim de Psicologia, vol. LVIII, n. 128, p. 55-72, 2008

ANDRADE, A. N. \& ALENCAR, H. M. de. Juízos de pessoas surdas sobre humilhação: passado e presente. Psicologia Escolar e Educacional, vol. 14, n. 2, p. 271-280, 2010.

ANDRADE, A. N. Ecos do Silêncio: juízos de surdos no âmbito da formação superior sobre projetos de vida e humilhação nas perspectivas moral e ética. 293 p. Tese (Doutorado em Psicologia). Programa de Pós-Graduaçáo em Psicologia, Universidade Federal do Espírito Santo, Vitória, 2012.

BISOL, C. A.; SIMIONI, J.; SPERB, T. Contribuiçôes da psicologia brasileira para o estudo da surdez. Psicologia Reflexão e Crítica, vol. 21, n. 3, p. 392-400, 2008.

COSTA, L. M. da. Traduçóes e marcas culturais dos surdos capixabas: os discursos desconstruídos quando a resistência conta a história. 186 p. Dissertaçáo (Mestrado em Educaçáo). Programa de Pós-Graduaçấo em Educação, Universidade Federal do Espírito Santo, Vitória, 2007.

COSTA, L. M. da. (Per)cursos na formação de professores de surdos capixabas: constituição da educação bilíngue no estado do Espírito Santo. 219 p. Tese (Doutorado em Educação), Programa de Pós-Graduação em Educação, Universidade Federal do Espírito Santo, Vitória, 2012.

DALCIN, G. Um estranho no ninho: um estudo psicanalítico sobre a constituição da subjetividade do sujeito surdo. 134 p. Dissertação (Mestrado em Psicologia), Programa de Pós-Graduaçẫo em Psicologia, Universidade Federal de Santa Catarina, Florianópolis, 2005.

LA TAILLE, Y. de. Moral e ética: dimensōes intelectuais e afetivas. São Paulo: Artmed, 2006.

LABORIT, E. O grito da gaivota. Tradução: Ângela Sarmento. 2 ed. Lisboa: Editorial Caminho, 2000. Originalmente publicado em 1994.

LANA, Z. M. de O.; CASTRO, F. G. A. S. de; MARQUES, S. M. F. Memória e identidade docente de uma professora surda do Ensino Superior. Educaçáo Especial, vol. 29, n. 54, p. 69-82, 2016.

LANE, H. Ethics and Deafness: Ethnicity, Ethics, and the Deaf-World. Journal of Deaf Studies and Deaf Education, vol. 10, n. 3, p. 291-310, 2005.

MARCHESI, A. Desenvolvimento e educação das crianças surdas. In: COLL, C.; MARCHESI, A.; PALACIOS, J. Desenvolvimento psicológico e educaçáa: transtornos de desenvolvimento e necessidades educativas especiais. Tradução: Fátima Murad. vol. 3. Porto Alegre: Artmed, 2004.

MIRANDA, W. de O. A experiência e a pedagogia que nós surdos queremos. 152 p. Tese (Doutorado em Psicologia). Programa de Pós-Graduação em Educação, Universidade Federal do Rio Grande do Sul, Porto Alegre, 2007.

NADER, J. M. V. Aquisiçáo tardia de uma língua e seus efeitos sobre o desenvolvimento cognitivo dos surdos. 148 p. Dissertaçáo (Mestrado em Linguística). Instituto de Estudos da Linguagem, Universidade Estadual de Campinas, SP, 2011.

NEMBRI, A. G. Ser surdo no mundo ouvinte. In: SILVA, A. C. da; NEMBRI, A. G. Ouvindo o silêncio: surdez, linguagem e educação. Porto Alegre: Mediação, 2008. 
PERLIN, G. T. T. Histórias de vida surda: identidades em questáo. 93 p. Dissertação (Mestrado em Educação). Programa de Pós-Graduação em Educação, Universidade Federal do Rio Grande do Sul, Porto Alegre, 1998.

PERLIN, G. T. T. O ser e o estar sendo surdos: alteridade, diferença e identidade. 156 p. Tese (Doutorado em Educação). Programa de Pós-Graduação em Educação, Universidade Federal do Rio Grande do Sul, Porto Alegre, 2003.

PIAGET, J. Seis estudios de Psicología. Tradução: Jordi Marfá. Barcelona: Editorial Labor, 1991. (Originalmente publicado em 1964).

RICOEUR, P. Caminos del reconocimiento: tres estudios. Tradução: Agustín Neira. Cidade do México: Fondo de Cultura Económica, 2006. (Originalmente publicado em 2004).

SIXEL, A. L. C. Análise pragmática de atos comunicativos de crianças surdas. Tese (Doutorado em Psicologia Social). Programa de Pós-Graduação em Psicologia Social, Universidade do Estado do Rio de Janeiro, 2005.

SKLIAR, C.; MASSONE, M.. I.; VEINBERG, S. El acceso de los niños sordos al bilinguismo y al biculturalismo. Infancia y Aprendizaje, Madrid, p. 69-70, 1995.

STROBEL, K. As imagens do outro sobre a cultura surda. 2. ed rev. Florianópolis: Editora da UFSC, 2009.

\section{Notas}

${ }^{1}$ Este artigo é derivado da tese de doutorado "Ecos do Silêncio: Juízos de surdos no âmbito da formação superior sobre projetos de vida e humilhaçāo nas perspectivas moral e ética", apresentada por Alline Nunes Andrade ao Programa de Pós-Graduaçáo em Psicologia da Universidade Federal do Espírito Santo, sob orientação da Profa Dra. Heloisa Moulin de Alencar. As autoras agradecem à Fundação de Amparo à Pesquisa e Inovação do Espírito Santo (FAPES) e à Coordenaçăo de Aperfeiçoamento de Pessoal de Nível Superior (CAPES), pelo apoio financeiro.

${ }^{2}$ Citaçấo original: "una visión estrictamente ligada a la patología, al déficit biológico, y deriva inevitablemente en estrategias y en recursos de índole reparador y correctivo.” (SKLIAR, MASSONE, VEINBERG, 1995, p. 2).

\section{Correspondência}

Alline Nunes Andrade - Programa de Pós-Graduação em Psicologia/UFES. Av. Fernando Ferrari, no 514, Campus Universitário de Goiabeiras/UFES, CEMUNI VI. CEP 29075-910. Vitória, Espírito Santo, Brasil.

E-mail: lineandrade@gmail.com - heloisamoulin@gmail.com

Recebido em 21 de outubro de 2016

Aprovado em 22 de maio de 2017 
